\title{
AN ECONOMIC APPRAISAL OF THE IMPACT OF TRAFFIC DIVERSION - THE N1 TOLL ROAD AND ITS ALTERNATIVE*
}

\author{
N.G MEYER, M BREITENBACH, RD KEKANA**
}

\begin{abstract}
This paper investigates two alternative roads running parallel to one another; one being a double carriageway national road that was tolled four years ago and the other being an inter-city singlecarriageway road. The purpose of the paper is to test the application of the World Bank-developed Road Economic Decision (RED) model for assessing the economic impact of traffic diversion between two existing alternative roads. In order to do so, the RED model is first used to conduct a cost-benefit analysis of each road in isolation. Thereafter, the model is used to do a scenario analysis followed by a sensitivity analysis. The results show that the RED model is a useful tool for evaluating the impact on society of diverted traffic between alternative roads elsewhere in South Africa.

Keywords: Cost-benefit analysis, Roads Economic Decisions model (RED)

JEL Classification: H42, 43
\end{abstract}

\section{INTRODUCTION}

The N1 Platinum Toll Route consists of an estimated $122 \mathrm{~km}$ of national road between Pretoria and Bela Bela (Warmbaths), running south - north. This is one of a number of Build Operate Transfer (BOT) toll road concessions that the South African National Roads Agency (SANRAL) put out to tender on a concession basis. The N1 North project is a good example of a Public Private Partnership (PPP). Private sector funding amounting to R650 million was used for the construction of tollgates, improvements to the existing road and the construction of new road surface. A state guarantee of stipulated monthly toll revenue over the 30-year concession period amounts to a present value of one billion Rand. The project involves upgrading of the existing N1 toll road and construction of new road surface and toll plazas at various strategic locations, including the provision of Electronic Toll Collection (ETC) gates. The Bakwena Platinum Corridor Consortium (BPCC) was appointed by SANRAL as scheme developer to implement the project. Bakwena has a contractual obligation to repair, maintain and rehabilitate the N1 toll for the duration of the 30-year concession (Bakwena, 2005).

The alternative route (R101) takes traffic from the northern suburbs of Pretoria, all the way to Bela-Bela and runs parallel to the N1. The stimulus for this research was that persons living along this older route had publicly expressed dismay over the introduction of toll-gates along the N1. They argued that tolling had diverted additional traffic to the R101, adversely affecting their quality of life. Public complaints over the introduction of user-fees (toll fares) suggested that some people living along the R101 had previously used the N1 to travel to and from work, and for other travelling purposes.

These events motivated a study of traffic patterns over a period of time and an

\footnotetext{
* Project economist, Development Bank of Southern Africa.

** Department of Economics, University of Pretoria and M Com student in the department of Economics, respectively.

The authors wish to thank an anonymous referee for proofreading the paper and for helpful recommendations on the linguistic and academic aspects of the paper.
} 
economic appraisal of the results obtained from the study of traffic patterns. Surveys among residents, road users and businesses provided the information needed to perform a comprehensive cost-benefit analysis using RED.

\section{THE AIM OF THE PAPER}

The purpose of this paper is to discuss the application of the RED model in respect of the economic appraisal of traffic diversion between two alternative roads. In this paper it is done as follows:

Section 3 briefly outlines the model. In section 4, some theoretical considerations of the RED model are briefly outlined. This is followed in sections 5 and 6 with an outline of economic costs and economic benefits, respectively. In section 7, the results obtained from the application of the model, both in terms of scenario and sensitivity analysis are discussed. Summary comments, conclusions and recommendations follow in section 8 .

\section{MODEL DEVELOPMENT}

The Road Economic Decision model (RED) was developed by the World Bank and customised for South African conditions by CSIR Transportek. Later refinements of the model were done by the University of Stellenbosh. The RED model (hereinafter referred to only as RED) computes benefits accruing to normal, generated and diverted traffic, as a function of a reduction in vehicle operating and time costs. It also computes safety benefits and model users can add other benefits (or costs) to the analysis, such as those related to non-motorised traffic, social service delivery and environmental impacts (Archando-Callao, 1999:2 \& Watanada et al., 1987).

RED adopts the consumer surplus approach, which measures the benefits to road users and consumers of reduced transport costs. This approach is accepted because it allows for a better judgement of the assumptions and provides an improved assessment of the investment alternatives simulated in the model. RED also simplifies the Cost Benefit Analysis (CBA) process and addresses the following additional concerns (Archando-Callao, 1999:2):

- Reduces input requirements for low volume roads

- Takes into account uncertainty related to input requirements

- Clearly states assumptions made

- Computes internally the generated traffic.

This approach is preferred to the producer surplus approach, which measures the 'value added' or benefits generated by productive users in a project's zone of influence, e.g. value added by agricultural producers. Both RED and Highway Design and Maintenance Standards (HDM) models adopt the consumer surplus approach in the CBA analysis. Although it can be used for the economic evaluation of low volume roads it is not customised for this purpose. HDM models are also more demanding and complex in terms of input requirements (Kerali, 2000:2). HDM models are more applicable to the evaluation of project alternatives where a new road is considered, as the input requirements include engineering specifications that are linked to the life span of the road. RED is therefore the only practical economic appraisal tool currently available to South Africa for the evaluation of existing roads. According to Archando-Callao (1999), "...despite the limitation of being more suited to low volume road applications, it is a simplified economic evaluation model that fulfils the planning and programming needs of 
highway agencies, without demanding unrealistic and costly input parameters while presenting the results in a practical and effective manner".

\section{THEORETICAL CONSIDERATIONS}

\section{Modelling considerations and concept}

The basic task of a CBA road model is to predict total life cycle costs, viz. construction, maintenance and road user costs as a function of road design, maintenance standards and other policy options. In certain circumstances an even broader definition of societal costs is necessary, e.g. where the costs of air pollution from road use suffered by non-road users are significant. Such external costs, if known, may be entered into the model through the exogenous benefits and costs facility. To have a generally applicable tool, the effects of different environments (terrain, climate, traffic, traffic behaviour, economic conditions) on the different cost relationships must be known.

The broad concept of RED is similar to that used by HDM and consists of three interacting sets of costs relationships that are added together over time in discounted present values, where costs are determined by first predicting physical quantities of resource consumption and then multiplying it by the unit costs or prices:

Construction costs = f1 (terrain, soils, rainfall, geometric design, pavement design, unit costs)

Maintenance costs $=\mathrm{f} 2 \quad$ (road deterioration-pavement design, climate, time, traffic, maintenance standards, unit costs)

Road user costs = f3 (geometric design, road condition, vehicle speed, vehicle unit costs)

Vehicle speed, which is a major determinant of vehicle operating costs, is related through a complex set of probabilistic functions to road geometric design, surface conditions, vehicle type and driver behaviour.

RED evaluates one road at a time comparing three project alternatives against the without-project case, yielding the investment efficiency indicators needed to select the most desirable alternative and to quantify its net economic benefits. For each project alternative, RED calculates the following investment efficiency indicators:

- Net present value of the given discount rate

- Internal rate of return

- Modified rate of return (considering the re-investment rate assumed at the given discount rate)

- Net present value per financial investment cost

- First year benefit cost ratio.

RED produces a detailed economic feasibility report for each project alternative, containing all main input assumptions as well as vehicle speeds, travel time, generated traffic, stream of net benefits, and economic indicators.

RED allows a sensitivity analysis of the uncertainty and project risks associated with changing input variables. This is done in the paper by performing a sensitivity analysis on the base case scenario and comparing it with the road agency (capital cost) and user net benefit streams for the N1 and the R101 routes. 


\section{ECONOMIC COSTS}

\section{(a) Terrain types}

Lebo \& Schelling (2002:37) state that a terrain through which a road leads can be conveniently classified as flat, rolling, or mountainous as defined by both subjective descriptions and average ground slope. Terrain type has a considerable impact on the nature of the drainage, alignment, and road structure performance after construction costs. Table 1 provides the definitions of terrain types, as given in the RED Software guide, as adapted for South Africa by CSIR Transportek.

Table 1. Definitions of terrain types

\begin{tabular}{|l|l|l|}
\hline Terrain type & Gradient (vertical alignment) & Curvature (horizontal alignment) \\
\hline Flat & $\begin{array}{l}0 \% \text { gradient for } 20 \% \text { of distance } \\
1 \% \text { gradient for } 40 \% \text { of distance } \\
2 \% \text { gradient for } 40 \% \text { of distance }\end{array}$ & $\begin{array}{l}\text { Curvature has no effect on vehicle } \\
\text { running cost }\end{array}$ \\
\hline Tangent and rolling & $\begin{array}{l}3,51 \% \text { gradient for } 75 \% \text { of distance; } \\
\text { remaining } 25 \% \text { consists of sag curves and } \\
\text { crest curves }\end{array}$ & $\begin{array}{l}\text { Curvature has no effect on vehicle } \\
\text { running cost }\end{array}$ \\
\hline Flat and winding & See "Flat" & $\begin{array}{l}\text { Curve with } 800 \text { metre radius for } 30 \% \text { of } \\
\text { distance and curve with radius }>3 \\
\text { metres for remaining } 70 \% \text { of distance }\end{array}$ \\
\hline Rolling & See "Tangent and rolling" & \begin{tabular}{l} 
See "Flat and winding" \\
\hline Mountainous
\end{tabular} \\
$\begin{array}{l}6,5 \% \text { gradient for } 75 \% \text { of distance; } \\
\text { remaining } \\
25 \% \text { consists of sag curves and crest curves }\end{array}$ & $\begin{array}{l}\text { Curve with } 400 \text { metre radius for } 30 \% \text { of } \\
\text { distance and curve with radius }>3000 \\
\text { metres for remaining } 70 \% \text { of distance }\end{array}$ \\
\hline
\end{tabular}

Source: CSIR Transportek, 2003.

(b) Ride quality

Ride quality is one of the parameters of road conditions (the others being surface distress and surface texture). Ride quality is measured by road roughness, i.e. the irregularity of road surface as it affects the dynamics of moving vehicles and wear-and-tear of vehicle parts.

Ride quality is an indication of the roughness of the road and is therefore an important parameter for indicating road condition and maintenance needs and for predicting vehicle operating costs. In RED, ride quality is expressed in terms of an International Roughness Index (IRI) and expressed in metre/kilometre $(\mathrm{m} / \mathrm{km})$. IRI estimates the road roughness as a function of the speed of a reference vehicle; similar cubic polynomials also need to be defined for the reference vehicle. According to Lebo \& Schelling (2002:6) IRI is defined mathematically as a summary statistic of the longitudinal profile in the wheel path of a travelled road surface. Table 2 provides guidelines on default values for different scenarios on bituminous (tar) roads (Watanada et.al., 1987).

When interpreting these values, it is important to bear in mind that, in a South African context (excluding the deep rural areas), values will typically fall in the "Good" and "Fair" columns. The likelihood that values will fall in the "Poor" and "Bad" columns respectively is "small" and "unlikely".

Table 2. Default values for ride quality: Bituminous roads

\begin{tabular}{|l|l|l|l|l|}
\hline \multirow{2}{*}{ Road class } & \multicolumn{4}{|l|}{ Ride quality (m/km IRI) } \\
\cline { 2 - 5 } & Good & Fair & Poor & Bad \\
\hline Primary or Trunk & 2 & 4 & 6 & 8 \\
\hline Secondary or Main & 3 & 5 & 7 & 9 \\
\hline Tertiary or Local & 4 & 6 & 8 & 10 \\
\hline
\end{tabular}

Source: CSIR Transportek, 2003. 
Given the fact that ride quality constitutes a critical input variable in the model, the user is recommended to refrain from selecting IRI values based on subjective judgment (even by so-called experts) and rather use values based on actual, scientific measurement of the road to be evaluated.

The estimated cost of collisions is given in Table 3, for four collision severity types, as well as a weighted average value. It is based on the cost of collisions to the economy as estimated by CSIR Transpotek that based their estimates on actual survey data.

Table 3. Collision cost data (March 2003 Rand)

\begin{tabular}{|l|l|l|l|}
\hline Collision severity & $\begin{array}{l}\text { Drivers and } \\
\text { passengers }\end{array}$ & Pedestrians & Weighted average value \\
\hline Fatal & 817036 & 267781 & 554538 \\
\hline Serious injury & 175413 & 71625 & 127492 \\
\hline Slight injury & 45901 & 9185 & 33254 \\
\hline Damage only & 22165 & 1376 & 21828 \\
\hline Weighted average value (both) & 33927 & 47328 & 34926 \\
\hline
\end{tabular}

Source: CSIR Transportek, 2003

\section{(c) Cost of travel time}

Estimates for the cost of travel time are presented in Table 4 below.

Table 4: Travel time cost data (March 2003 Rand)

\begin{tabular}{|l|l|l|l|}
\hline Income group & $\begin{array}{l}\text { Value of a } \\
\text { work hour }\end{array}$ & $\begin{array}{l}\text { Value per recreational } \\
\text { hour for all persons }\end{array}$ & $\begin{array}{l}\text { Value per recreational } \\
\text { hour for workers }\end{array}$ \\
\hline Low income group & 6.88 & 0.29 & 1.57 \\
Middle income group & 24.64 & 1.82 & 5.62 \\
High income group & 53.51 & 5.03 & 12.20 \\
Total population & 19.90 & 1.20 & 4.54 \\
\hline
\end{tabular}

Source: CSIR Transportek, 2003

(d) Daily traffic and traffic growth

According to the Road Traffic and Fatal Crash Statistics held by the National Roads Agency (Mikros Traffic Monitoring, 2005) the average daily traffic (ADT) per national road increased by 3,14 percent from 19137 vehicles per day in 2002 to 19775 per day in 2003. From 2003 to 2004 the increase was 5,15 percent to an average of 20794 vehicles per day. This is illustrated in Figure 1 below.

Figure 1. Daily traffic volumes, 2002 - 2004

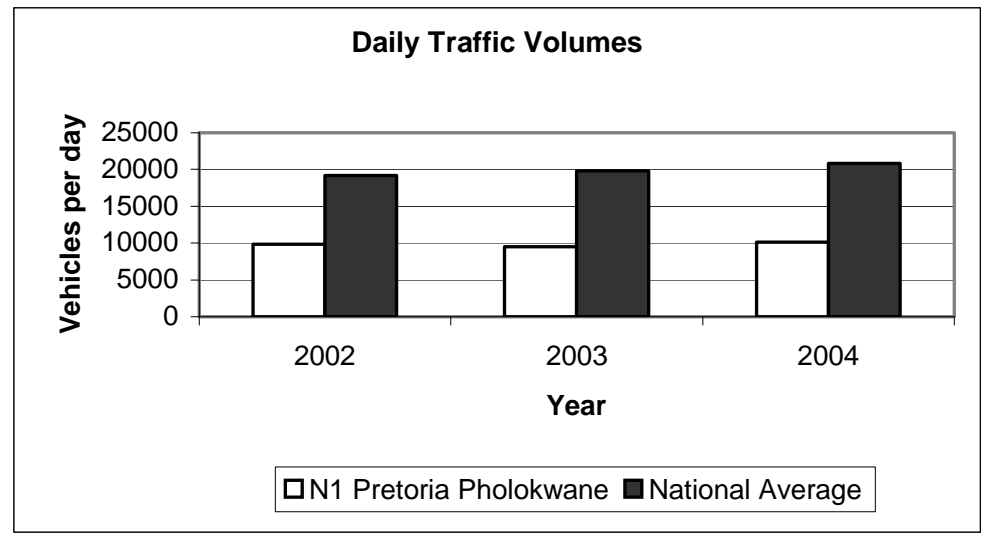

Source: Mikros Traffic Monitoring, 2005. 
The ADT on the Pretoria/Polokwane N1 route decreased by an average rate of 3,5 percent from 9839 in 2002 to 9494 in 2003 . From 2003 to 2004 it increased again 6,71 percent to an average of 10313 vehicles per day. Trend analysis of time series data shows an exponential growth rate of 1,5 per cent from 2002 to 2004.

Tables 5 and 6 present a twenty year projected ADT of the R101 and N1, based on the assumed growth rates. Note that the start and end years differ by one year as a result of insufficient data. As the CBAs for the two roads are run separately and taken over a twenty year period, the impact thereof is insignificant.

Table 5. R101 - Daily Traffic and Vebicle Composition

\begin{tabular}{|c|c|c|c|c|c|c|c|c|}
\hline \multirow[b]{2}{*}{6} & \multirow{2}{*}{$\begin{array}{l}\text { ADT } \\
2003 \text { (veh/day) }\end{array}$} & \multirow{2}{*}{$\begin{array}{l}\text { Composition } \\
2003(\%)\end{array}$} & \multirow{2}{*}{$\begin{array}{l}\text { ADT } \\
2022\end{array}$} & \multirow{2}{*}{$\begin{array}{l}\text { Composition } \\
2022(\$)\end{array}$} & \multicolumn{4}{|c|}{ Traffic Growth Rate (\%) } \\
\hline & & & & & 2003 & -2008 & $-2013-2017$ & $2018-2022$ \\
\hline Car & 7153 & $88.82 \%$ & 12389 & $91.93 \%$ & 3.94 & 3.00 & 2.50 & 2.50 \\
\hline Utility & 0 & $0.00 \%$ & 0 & $0.00 \%$ & 1.00 & 1.50 & 1.50 & 1.50 \\
\hline Light Bus & 0 & $0.00 \%$ & 0 & $0.00 \%$ & 1.00 & 1.50 & 1.50 & 1.50 \\
\hline Medium Bus & 0 & $0.00 \%$ & 0 & $0.00 \%$ & 1.00 & 1.50 & 1.50 & 1.50 \\
\hline Heavy Bus & 0 & $0.00 \%$ & 0 & $0.00 \%$ & 1.00 & 1.50 & 1.50 & 1.50 \\
\hline Light Truck & 400 & $4.97 \%$ & 483 & $3.59 \%$ & 1.00 & 1.00 & 1.00 & 1.00 \\
\hline Medium & 300 & $3.73 \%$ & 362 & $2.69 \%$ & 1.00 & 1.00 & 1.00 & 1.00 \\
\hline Heavy Truck & 200 & $2.48 \%$ & 242 & $1.79 \%$ & 1.00 & 1.00 & 1.00 & 1.00 \\
\hline Artic. Truck & 0 & $0.00 \%$ & 0 & $0.00 \%$ & 1.00 & 1.50 & 1.50 & 1.50 \\
\hline Total & 8053 & $100.00 \%$ & 13477 & $100.00 \%$ & & & & \\
\hline Weighted & 7153 & & & & 3.61 & 2.78 & 2.33 & 2.33 \\
\hline
\end{tabular}

Source: Mikeros Traffic Monitoring, 2005.

Table 6. N1 Toll Road - Daily Traffic and Vehicle Composition

\begin{tabular}{|c|c|c|c|c|c|c|c|c|}
\hline & \multirow{2}{*}{$\begin{array}{l}\text { ADT } \\
2002 \text { (veh/day) }\end{array}$} & \multirow{2}{*}{\begin{tabular}{|l|} 
Composition \\
$2002(\%)$
\end{tabular}} & \multirow{2}{*}{$\begin{array}{l}\text { ADT } \\
2021 \text { (veh/day) }\end{array}$} & \multirow{2}{*}{$\begin{array}{l}\text { Composition } \\
2021(\$)\end{array}$} & \multicolumn{4}{|c|}{ Traffic Growth Rate (\%) } \\
\hline & & & & & $2002-2006$ & $2007-2011$ & $2012-2016$ & $2017-2021$ \\
\hline Car & 13146 & $86.74 \%$ & 15882 & $82.97 \%$ & 1.00 & 1.00 & 1.00 & 1.00 \\
\hline Utility & 0 & $0.00 \%$ & 0 & $0.00 \%$ & 0.00 & 0.00 & 0.00 & 0.00 \\
\hline Light Bus & 0 & $0.00 \%$ & 0 & $0.00 \%$ & 0.00 & 0.00 & 0.00 & 0.00 \\
\hline Medium Bus & 0 & $0.00 \%$ & 0 & $0.00 \%$ & 0.00 & 0.00 & 0.00 & 0.00 \\
\hline Heavy Bus & 0 & $0.00 \%$ & 0 & $0.00 \%$ & 0.00 & 0.00 & 0.00 & 0.00 \\
\hline Light Truck & 565 & $3.73 \%$ & 916 & $4.79 \%$ & 3.50 & 3.00 & 2.00 & 2.00 \\
\hline Medium Truck & 637 & $4.20 \%$ & 1033 & $5.40 \%$ & 3.50 & 3.00 & 2.00 & 2.00 \\
\hline Heavy Truck & 808 & $5.33 \%$ & 1310 & $6.85 \%$ & 3.50 & 3.00 & 2.00 & 2.00 \\
\hline Artic. Truck & 0 & $0.00 \%$ & 0 & $0.00 \%$ & 0.00 & 0.00 & 0.00 & 0.00 \\
\hline Total & 15156 & $100.00 \%$ & 19141 & $100.00 \%$ & & & & \\
\hline Weighted Average & e 13146 & & & & 1.33 & 1.27 & 1.13 & 1.13 \\
\hline
\end{tabular}

RED assumes a price elasticity of demand for transport of 1.0 for all vehicles, meaning that a one percent decrease in transport costs yields a one percent increase in generated traffic due to reduction in transport costs. This assumption is based on several case studies using RED, which intimated that this elasticity remains at around 1 for all of the studies (see Archondo-Callao, 2004). If one does not include generated traffic in the analysis, the price elasticity is equal to 0 (Archondo-Callao, 2004). This means that RED will compute internally the generated traffic as a function of the reduction in road user costs in relation to the 'without project' case road user cost.

The average daily toll road traffic as measured by BPCC is presented in Table 7 . Vehicle traffic on the N1 between the Pumulani and Carousel Toll Plazas decreased at a rate of 0,71 percent between 2002 and 2004. In contrast, average daily truck traffic (ADTT) grew at a rate of 3, 5 percent over the corresponding period. The composition of traffic shows that trucks comprised an average of 13,2 percent of the total traffic. 
Table 7. Average daily traffic, $2002-2004$

\begin{tabular}{|c|c|c|c|c|}
\hline & 2002 & 2003 & 2004 & $\%$ Change 2002-4 \\
\hline \multicolumn{5}{|l|}{ Toll Pumulani Plaza } \\
\hline Total number of vehicles & 1754372 & 6176326 & 6391313 & \\
\hline Average daily traffic (ADT) & 18027 & 16923 & 17477 & $-1.54 \%$ \\
\hline Average daily truck traffic (ADT'T) & 2173 & 2153 & 2255 & $1.87 \%$ \\
\hline Percentage of trucks: & 12.1 & 12.7 & 12.9 & \\
\hline Short & 652 & 603 & 654 & \\
\hline Medium & 761 & 754 & 744 & \\
\hline Long & 761 & 797 & 857 & \\
\hline \multicolumn{5}{|l|}{ Toll Carousel } \\
\hline Total number of vehicles & 3465269 & 4291646 & 4645362 & \\
\hline Average daily traffic (ADT) & 12396 & 11993 & 12836 & $1.76 \%$ \\
\hline Average daily truck traffic (ADT'T) & 1581 & 1640 & 1767 & $5.72 \%$ \\
\hline Percentage of trucks: & 12.8 & 13.7 & 13.8 & \\
\hline Short & 490 & 443 & 477 & \\
\hline Medium & 458 & 508 & 530 & \\
\hline Long & 632 & 689 & 760 & \\
\hline \multicolumn{5}{|l|}{ R101 (Bon Accord) } \\
\hline Total number of vehicles & 2476186 & 4298191 & 4531890 & \\
\hline Average daily traffic (ADT) & 10973 & 11886 & 12395 & $6.28 \%$ \\
\hline Average daily truck traffic (ADTT) & 1199 & 1186 & 1219 & $0.83 \%$ \\
\hline Percentage of trucks: & 10.9 & 10 & 9.8 & \\
\hline Short & 528 & 534 & 549 & \\
\hline Medium & 444 & 427 & 439 & \\
\hline Long & 228 & 225 & 232 & \\
\hline
\end{tabular}

Source: Mikros Traffic Monitoring, 2005.

Trend analysis of vehicle traffic on the R101 shows a significant growth in light vehicle traffic $(3,9$ per cent) compared to a very low growth in truck traffic $(0,05$ percent $)$ between 2002 and 2005. The relative composition of truck traffic to total traffic also decreased from 10,9 percent to 9,8 per cent. The general increase in traffic on the R101 may be the cause of generated traffic as a result of an increase in local economic development and urbanisation in the surrounding northern suburbs or generated traffic as a result of traffic diverted from the N1 to the R101.

(e) Traffic diversion

Residents along the R101 believe that the congestion experienced along the R101 is the result of a large number of vehicles diverted from the N1 as a result of the avoidance of toll fees. Bakwena (2005) is of the opinion that there was an initial diversion of traffic when the toll road came into operation, but that it slowly filtered back after six months. According to Bakwena new entrants are using the toll road and the traffic is growing normally as expected. Bakwena believes that truck drivers are instructed to stick to the toll road. Because it is not possible to accurately determine which part of the increase or decrease in traffic on each of the routes is induced as a result of normal traffic growth and which as a result of traffic diversion, some assumptions are required. For purposes of this cost benefit analysis it is assumed the traffic diversion would not comprise more than 10 percent of the ADT on the R101. This is done using scenario and sensitivity analysis (section 6).

(f) Route description

For purposes of this analysis, two routes are compared, namely the N1 Toll and R101 routes. These routes cover distances of $41 \mathrm{~km}$ and $55 \mathrm{~km}$ respectively. The N1 Toll route is a dual carriageway of which the distance was measured from Zambesi Plaza to the 
Carousel Plaza. It has no stops or congestion points except at the toll plazas. The alternative route, i.e. the R101, is a single carriageway and its distance was measured from the Zambesi off-ramp to the Carousel Plaza. It has a number of stops including traffic lights.

(g) Vehicle operating costs and speeds

The relationship between vehicle operating costs (VOC) and roughness to speed ratios for nine possible combinations of terrain and road types and nine possible vehicle types are modelled in RED (Lebo \& Schelling, 2002:8). Here the relationship between roughness to the speed of the reference vehicle for nine possible combinations of terrain and road types is defined. All these relationships take the form of cubic polynomials Archondo-Callao, 1999:3). For example:

$\operatorname{VOC}(\mathrm{R} /$ vehicle-km) as a function of roughness (IRI):

VOC $=a 0+a 1 * I R I+a 2 * I^{2} I^{2}+a 3 * I^{2} I^{3}$

Where IRI = International Roughness Index

a1, a2, a3 = coefficients for the cubic polynomials derived from the

hdm-3 or hdm- 4 vehicle operation cost and speed equations

adapted for South Africa

(b) Road construction costs

The road construction cost constitutes one of the basic elements of the cost-benefit analysis. Construction costs usually include cost items such as acquisition, design, supervision, and construction costs. The N1 was constructed in the mid 1970's as a double carriageway and no accurate figures are available on its construction and maintenance costs. Due to the fact that the toll road was put into operation much later in 2002, 2002 was taken as a starting year for the construction of the toll road in the CBA model. The construction costs used in the model are based on similar road projects, which were constructed more recently, but inflated by the production price index to 2003 prices (the starting year of the analysis). Some benchmark figures used in simulating construction costs are listed in Table 8.

Table 8. Benchmark Construction Costs for double carriageway roads (at 2003 prices)

\begin{tabular}{|l|l|l|l|l|l|}
\hline Toll Road & $\begin{array}{l}\text { Capital cost } \\
\text { (Rand) }\end{array}$ & $\begin{array}{l}\text { Length } \\
\text { (km) }\end{array}$ & $\begin{array}{l}\text { Cost/km } \\
\text { (R/km) }\end{array}$ & $\begin{array}{l}\text { Construction } \\
\text { Year }\end{array}$ & $\begin{array}{l}\text { Cost/km } \\
(\mathbf{2 0 0 3 )}\end{array}$ \\
\hline Maputo toll Road & 1400000000 & 532 & 2631579 & 1997 & na \\
N 3toll road & 2200000000 & 424 & 5188679 & 2001 & 6122449 \\
N17 toll road project & 769300000 & 164 & 4690854 & 2000 & 5966766 \\
\hline
\end{tabular}

Source: $D B S A, 2006$.

The model assumes that in the absence of realistic construction cost estimates, the construction cost of the N3 Toll Road would represent a realistic proxy of the expected construction cost of the N1 North Toll Road. In the case of the R101, the construction cost is assumed to be between R2 million and R3 million per kilometre. Again estimates were obtained from DBSA (2006) and based on the same simulation procedure as the N1.

(i) Maintenance and operating costs

Road maintenance cost estimates includes both the routine and periodic maintenance cost (including reseals), for all project alternatives, appropriately spread over the period of 
the analysis. For the maintenance and operating costs of the toll road the contracts of existing toll roads are considered. To achieve and maintain a level of service, an initial investment and annual maintenance cost (fixed [non-traffic dependant] and variable [traffic dependent]) are specified by the model user. Because variable maintenance costs are dependant on the volume of traffic, it is estimated using estimated growth in traffic scenarios over the lifetime of the project. In the case of this study, this exercise was done by Bakwena and is reflected in Table 9 .

Table 9. Estimated maintenance cost per kilometre in $\mathrm{R}$ per kilometre per annum, 2003

\begin{tabular}{|l|l|l|}
\hline Maintenance cost & N1 North $(\mathbf{R}$ per $\mathbf{~ k m} / \mathbf{a})$ & R 101 $(\mathbf{R}$ per km/a) \\
\hline $\begin{array}{l}\text { Fixed maintenance (weighted per } \\
\text { annum cost) }\end{array}$ & 50000 & 40000 \\
\hline $\begin{array}{l}\text { Variable maintenance (weighted per } \\
\text { annum cost) }\end{array}$ & 20000 & 20000 \\
\hline Total & 70000 & 60000 \\
\hline
\end{tabular}

Source: Bakwena, 2005.

(j) Data requirements of the model

RED was originally designed for applications pertaining to low volume roads. As mentioned earlier in the paper, Archando-Callao (1999), found that "...despite the limitation of being more suited to low volume road applications, it is a simplified economic evaluation model that fulfils the planning and programming needs of highway agencies, without demanding unrealistic and costly input parameters while presenting the results in a practical and effective manner". The major shortcomings are overcome by including default values for technical data based on an HDM model when adapting the RED model for South Africa.

The model is an abstraction of the reality. This means that one needs to construct a model that simulates reality, based on accurate assumptions. These assumptions need to reflect reality; therefore accuracy of the data is of paramount importance and need to be verified beyond any doubt.

\section{ECONOMIC BENEFITS}

Economic benefits are generally classified as intra- or extra-sectoral.

(a) Intra-sectoral benefits

Intra-sectoral benefits occur within the transport system of the project region and can be categorised as follows (Brathen, 2001):

- A reduction in either vehicle running cost or transport fares;

- Reduced risk of accidents

- Savings in travel time

- Increased comfort and convenience.

Intra-sectoral benefits are easily quantifiable and the measurement of these benefits should proceed according to the group of transport users within the project region to whom these benefits accrue. For this purpose three categories of transport users are identified:

- Existing users of the facility

- Diverted transport users, i.e. when traffic demand is transferred from other modes of the public transport network and from the road network

- Generated transport users, i.e. people who have not travelled before. 
(b) Extra-sectoral benefits

Extra-sectoral benefits result from the proposed project's effects on non-transport activities in the economy. Two broad categories of extra-sectoral benefits can be identified.

\section{(i) Effects on local economic development}

The construction of a project, such as a road project, could stimulate the local economy through multiplier effects if the factors of production in the economy are underemployed. Should the factors of production in the economy be fully employed, it can, however, result in a disadvantage because the project will have to compete with other sectors of the economy for required resources during implementation.

Changes in transport conditions, manifesting through effects on capacity, quality and cost of public transport can also stimulate local economic development. These benefits accrue if a public transport project releasing latent economic advantages of a specific kind is involved, or when business is attracted to a region because of the availability of favourable transport conditions resulting from the implementation of such a project. These benefits are usually quantified via the changes that occur in land prices within the project region as a result of the implementation of a public transport project.

A secondary impact on the economy can result from the implementation of a proposed project, i.e. investment in public road infrastructure can stimulate further investment in infrastructure. This could lead to lower prices of goods and services and the creation of more business opportunities in the project area.

(ii) Effects on society as a whole

The implementation of public road projects can have direct effects on non-users of roads. These effects are difficult or impossible to quantify because they are generally collective commodities for which no market exists. For this reason effects such as visual intrusion and disturbance to the landscape are often regarded as intangible. Other effects, such as air pollution and noise disturbance, can, however, be quantified via the cost implications of reducing their impact to levels that are acceptable to society through, for example, exhaust emission legislation or the erection of noise barriers (Brathen, 2001). These effects could not be quantified in monetary terms. Because of their importance however, they are included in the section of non-monetised items. The non-monetised items are as follows:

- Impact on natural environment

- Impact on tourism

- Impact on animal crossings

- Impact on pedestrian crossings

In RED economic benefits are derived from user benefits, which are a function of savings in VOC and time of normal and generated traffic or saving due to an improvement in road safety, resulting from improved roads. A decrease in traffic has a measurable effect on vehicle travel speed and time only when roads are significantly congested (i.e. operating at less than free flow speed).

\section{MODEL RESULTS: SCENARIO- AND SENSITIVITY ANALYSIS}

Scenarios can be chosen to draw attention to the main uncertainties upon which the success of a proposal depends. A common approach is to tests three combinations of key variables namely: Pessimistic Scenario, Base Scenario, and Optimistic Scenario. Scenario 
analysis is the simplest form of sensitivity analysis found in risk models with several sets of assumptions about key variables (The Treasury, 2005:38).

In the case of the R101 alternative route, two scenarios are tested under aforementioned assumptions to simulate the impact of diverted traffic from the N1 North as follows:

- Scenario 1 simulates the current situation (including an assumed 10 percent traffic diversion from the N1), with $\mathrm{ADT}$ of 8053 vehicles. It is assumed that traffic congestion on the road due to a 10 percent increase in ADT volumes would lead to lower speeds, which affects VOC and travel time. It would also result in more accidents, which is a cost to the economy.

- Scenario 2 simulates normal ADT excluding diverted traffic, estimated at about 90 percent of the current ADT. The natural growth rate in traffic volumes is assumed to be the same as for Scenario 1. It is expected that there would be less congestion, which affects VOC and travel time. This would result in a decreased accident rate.

Results of the two scenarios modelled are given in Table 10, together with the Base Scenario on the N1.

Table 10. RED model results

\begin{tabular}{|l|l|l|}
\hline Scenarios & IRR\% & NPV (R million) \\
\hline R101 & & \\
\hline Scenario 1 & 16.1 & R 52 \\
\hline Scenario 2 & 38 & R 367 \\
\hline N1 North Toll & 27,8 & R 349 \\
\hline
\end{tabular}

Source: Results generated by the RED Model.

The net present value (NPV) is used in the economic CBA to compare project alternatives (Scenario $1 \&$ 2), i.e. the 'without project' with 'bring to fair'". The without project scenario refers to a situation where nothing is done to induce traffic diversion to the N1 route. The bring to fair option, refers to a situation where routine maintenance is done on the R101 and simultaneously, 10 percent of current ADT is diverted from the R101 to the N1. In the case of the R101, Scenario 2 has the highest NPV of R367 million, thus indicating that it is the most feasible option economically, between the two scenarios considered.

In the case of Scenario 1, frequent maintenance needs to be performed under increased traffic. Increased traffic causes congestion and increased accidents and travelling time, which is a cost to the economy. Under Scenario 2, it is assumed that ADT will return to normal ( 90 percent of current ADT). Due to lower levels of congestion, travelling times would be faster, while maintenance costs and accident rates would decrease.

Results show that in the case of the N1 the construction of the road (without tolling) is economically feasible with an internal rate of return of 27,8 percent and a NPV of R349 million.

The final results make it clear that the R101 cannot cope with the current level of traffic and congestion. In the current application of RED, the economic impact of traffic diversion is tested, on the basis of a 10 percent diversion (reduction). The result indicates that in the case of the R101, which carries a high volume of traffic, a relatively small diversion (reduction) of 10 percent can make a substantial difference to the social (and

1 'without project' and 'bring to fair' are standard phrases used in the RED Model 
economic) profitability of the R101. In respect of the R101, a 10 percent reduction in ADT causes the NPV to increase from R52 million to R367 million, while the IRR improves from 16, 1 to 38 percent. Theory has it (see Nas, 1996: 38) that where a reduction in consumption leads to an improvement in social returns, the marginal social cost is higher than the marginal social benefit, and there is over-utilisation of the resource or public project. In order to derive a solution, the negative externalities imposed here on third parties should be identified and ways found to internalise it by either imposing some sort of additional tax on the use of the R101, or by imposing qualitative control over the use of the R101. The model suggests that a diversion away from the R101, to the tune of 10 percent, would then substantially improve the social returns of the road to society.

- Sensitivity analysis

The economic feasibility results for the option 'Bring to fair' demonstrate the effect of sensitivity analysis performed on the results. Table 10 presents the net benefits and the economic indicators such as the NPV, IRR, etc. It also presents the results of a basic sensitivity analysis on the base case vs. road agency (capital investment cost) and user net benefit streams for the N1 North and R101 alternative route. A sensitivity change of 25 percent is applied to the net benefit stream, i.e. 75 or 125 percent of the net benefit stream.

The results clearly show that in each case the base case, which has the highest NPV, is the most feasible option. It could be expected that a rise of 25 percent in the investment cost and a decrease in the user net benefit stream would result in a decrease in NPV and the IRR, respectively in each case.

The results of the sensitivity analysis are presented in Table 11 below.

Table 11. Sensitivity analysis

\begin{tabular}{|l|l|c|c|c|}
\hline Road & & IRR $\%$ & NPV $\mathbf{( R m )} *$ & Factor \\
\hline R101 (Scenario 1) & Base case & 16 & 52 & 1 \\
& Agency..a & 13 & 28 & 1.25 \\
& User.....b & 12 & 15 & 0.75 \\
R101 (Scenario 2) & a \& b & 9 & -7 & 1 \\
& Base case & 38 & 366 & 1.25 \\
& Agency..a & 33 & 343 & 0.75 \\
& User.....b & 32 & 251 & 1 \\
& a \& b & 27 & 228 & 1.25 \\
& Base case & 28 & 349 & 0.75 \\
\hline
\end{tabular}

- Discounted at 10 percent. Agency - investment cost. User - user net benefit stream. Factor Sensitivity factor i.e. $0.75=75$ percent.

Source: RED model results.

\section{SUMMARY COMMENTS, CONCLUSIONS AND RECOMMENDATIONS}

The first part of this section is devoted to general summary remarks, some of which are based on the non-monetised empirical evidence collected during the initial survey.

(a) Development impact

In the case of R101, the development impact of the existing road infrastructure, despite 
certain externalities, is in general positive. The growth in traffic, whether caused by diverted traffic or not, will stimulate local economic development along the R101. This was confirmed by the survey results of the empirical survey, which indicates an increased level of business opportunities and employment along the R101.

The N1 North tender stipulates that 12,5 percent of the contract value - this is a minimum of R50 million - is spent on the empowerment of SMME's, training and job creation. Small businesses and subcontractors are given the opportunity to borrow money at the same rate as large corporate companies.

\section{(b) N1 toll road and R101}

Without a national infrastructure there can be no trade, and little economic development or marginal improvement in the quality of life of South Africa's citizens. For one industry to function, its production process requires, as inputs, the goods or services produced (output) by other industries. In addition wages circulate in the economy as part of household expenses. In this manner, each Rand of spending on transportation stimulates additional spending, affecting other industries in the economy; this is known as the multiplier effect. Therefore, expenditure to build and maintain infrastructure and operate transportation services could influence a local or regional economy. The greatest problem in road infrastructure is the funding. In South Africa, the strategy of employing private sector funds and establishing the user-pay principle on toll roads was mainly implemented as a result of a shortage of state funds for road construction. This gave rise to toll roads such as the N1 North.

The R101 is an inter-city route that is the responsibility of the local government sphere and the N1 North a national road meant to carry traffic between cities. It is unfortunate that land use planning resulted in such an awkward situation where a national road is directed right next to an inter-city route, initially for the convenient and free use of the citizens living and working along an alternative route. The alternative route during this time (exceeding 30 years), was not attended to by the local municipality the way it should have been. Then, without much warning and without preparing the inter-city route for possible increased traffic, a toll system was introduced on the national road. Some recommendations follow in regard to the obligation of government to provide road infrastructure.

\section{(c) International experience}

It is important to view toll roads within an international context. International research shows that most countries have no toll roads. Where there are toll roads the tolled network typically comprises less than 5 percent of the road network. In most countries with toll roads the private sector has been heavily involved in development of the roads and often thereafter in their operation. Even where toll roads are operated by the private sector, government support has been considerable, in almost all cases. The funds from toll revenues can be dedicated to the construction and maintenance of a particular road thereby ensuring that maintenance funds in particular do not compete with the maintenance requirements of other roads in the network.

Diversion of traffic. Price elasticity of demand and the provision of free alternatives to the tolled road, will affect the level of traffic. In turn, this may mean that some potential economic benefits of the new road are lost since the objective of new road provisioning is to move people and goods more reliably and quickly. However, when well designed the cost of tolling for revenue should be lower than those of any other system of revenue 
collection. As a rule, toll fees should not exceed 75 percent of the savings realised by the public using the tolled road.

Social impacts. Just as with any road, toll roads can have significant social impact in the manner and location of their construction and in their operation. These can be both positive (providing improved access for some regions of a country) and negative (degrading the environment around the road, for example underneath an elevated urban expressway). However, there are additional consequences, which result from the tolls. For example, tolls

- can discourage unnecessary trips and therefore provide environmental benefits,

- may be too high for the poor to benefit from the new facilities, or

- may be so high that traffic diverts off the new road onto parallel roads, which pass through residential neighbourhoods, thereby reducing the benefits that the new road could have provided.

Toll fees should therefore be monitored to comply with the affordability criteria.

Cross subsidisation. The argument in favour of free parallel roads is one of social equity, to ensure that the poor also have access to the road network.

Other concerns about cross subsidisation relate to the question of transferring resources from one group of consumers to another. Those who are paying tolls on the existing road are thereby paying for the construction of a new road, which would provide benefits for other future users. This may be part of a government programme of regional development but needs to be explicitly recognised.

(d) Discussion of results

With the exception of major former homeland cities, the main urbanisation growth dynamics and rural urbanisation are oriented towards towns in white South Africa with population concentrations occurring along the former homeland (Bophuthatswana) perimeter. The majority of these migrating people are expected to urbanise in the four primary metropoles. A feature of the current pattern of urbanisation in South Africa, as in other developing countries, is the establishment of vast squatter communities due to a shortage of formal housing. Apart from urbanisation trends it could also be assumed that traffic is diverted from the Pretoria North Municipal area onto the R101, which is a shorter route. A proper assessment of the traffic composition and diversion needs to be performed in order to arrive at a realistic situation analysis.

In the application of the RED model, economic benefits are derived from user benefits, which is a function of savings in VOC's and time of normal and generated traffic on a road or saving due to an improvement in road safety, resulting from improved roads. A decrease in traffic has a measurable and sizable impact on vehicle travel speeds and travel time only when the roads are significantly congested (i.e. operating at less than free flow speed). Other non-quantifiable costs and benefits were not considered in this modelling exercise, but treated separately from the model.

In the case of scenario 1 (including diversion), frequent maintenance needs to be performed under increased traffic. Increased traffic due to 'diverted traffic', implicitly assumed in the 'without scenario', causes congestion (an increase) in accidents and travelling time, which is a cost to the economy. Under scenario 2, (excluding diversion), it is assumed that ADT will return to normal (normality assumed at 90 percent of current ADT). Due to lower levels on congestion, travelling times would be faster, while maintenance costs and accident rates would decrease. Scenario 2 is selected as being economically the most feasible option. 
(e) Conclusions

In respect of the R101, a 10 percent reduction in ADT causes the NPV to increase from R52 million to R367 million, while the IRR improves from 16, 1 percent to 38 percent. The model suggests that a diversion away from the R101, to the tune of 10 percent, would substantially improve the social returns of the road to society.

(e) Recommendations

It is recommended that:

The nature and extent of diversion of traffic from the N1 to the R101 be investigated more closely. Further to this, it is important to realise that on the assumption that no major improvements and expansion of the existing R101 are done, ways are found to internalise the current externalities, hence diverting traffic to the N1 to an extent that would equilibrate the social returns to society of the two routes.

It is proposed that traffic diversion from the R101 to the N1, which would increase the social profitability of the R101, or increased returns to society of using the R101, could be achieved by:

- providing toll concessions to residents along the N1 route.

- monitoring toll fees on a regular basis to ensure that the toll fees are affordable

- upgrading the R101 to a level that could handle larger traffic volumes (possibly converting it to a double carriageway).

- taking immediate corrective action to provide more alternative roads for inner-city travel and upgrade and maintain the existing $\mathrm{R} 101$ route.

\section{REFERENCES}

ADAM, J. (1994). The Role of Cost Benefit Analysis in Environmental Debates, UK: Oxford Green College.

ARCHONDO-CALlaO, R.S. (1999). Road Economic Decision Model(RED) for Economic Evaluation of Low Volume Roads. Africa Transport Technical Note, Road Management Initiative (RMI) SSATP Note No 18, World Bank, USA, Washington DC.

ARCHONDO-CALlaO, R. (2004). Economically Justified Levels of Road Works Expenditures on Unpaved Roads. Transport Notes. Road and Rural Transport Thematic Group, Transport Note No: TRN-2, World Bank, USA, Washington DC. Also available on the site: http//www.worldbank.org./html/pdf/transport/publicat/pub-main.htm.

BAKWENA PLATINUM CONSORTIUM CONCESSIONAIRES. (2000). Environmental Impact assessment for the proposed platinum highway from warmbaths via Pretoria to skilpadhek on the South African Botswana border. Socio - Economic Environment vol 3. Bohlweki Environmental.

BAKWENA PLATINUM CORRIDOR CONSORTIUM (BPCC). (2005). Bakwena N1N14Toll Route Info Pack.

BOAdway, R.(2000). Principles of Cost Benefit Analysis, Public Policy Review, Vol:2 No:1 P1 - 42.Canada, Kingston.

BRATHEN, S. (2001). Economic Impact Assessment. Lecture notes. Norway. Molde University.

CAMPBeLL, H.F. \& BROWN, R.P.C. (2003). Benefit Cost Analysis, Financial and Economic Appraisal Using a Spreadsheet, UK, Cambridge University Press.

CONNINGARTH ECONOMISTS. (2002). Updating of the manual for cost - benefit analysis in South Africa to 2000 with Reference to Water Resource Development. First draft for 
discussion. No K5/1132 Pretoria

CSIR TRANSPORTEK. (2005). Operational information. Pretoria. CSIR Transportek.

DBSA. (2006). Development Bank of Southern Africa. 2006. Personal communication (Peter Copley - Transport specialist). Midrand.

DEAT. (2004). Cost Benefit Analysis, integrated environmental management, Information Series 8, Department of Environmental Affairs \& Tourism (DEAT) S.A, Pretoria.

EC REgIONAL POLICY. (1997). Guide to Cost Benefit Analysis of Major Projects, 1997 Edition.

GWILliAM, K. (2000). Evaluation Methodologies for Infrastructure Investment and Urban Sprawl. Transport Project Appraisal at the World Bank, World Bank, USA, Washington DC.

KERALI, H. (2000). Overview of the HDMA. World Bank.USA. Washington.DC, Http//Www.Hdm4.Plarc.Org.

LAYARD, R. \& GLAister, S. (eds). (1994). Cost Benefit Analysis, $2^{\text {nd }}$ edition, UK, Cambridge University Press.

LeBO, J. \& SCHELling, D. (2002) Design and Appraisal of Rural Transport Infrastructure, World Bank Technical Paper No: 496. USA. Washington.

Mikros TRAFFIC MONITORING (PTY) LTD. (2005). Operational data. Pretoria.

MisHAN, E.J. (1971). Cost Benefit Analysis an Informal Introduction, Unwim brothers Limited. p454.

NAS, T.F. (1996). Cost Benefit Analysis, Theory and Application, Sage Publications Inc. p219.

PIENAAR, W.J. \& BESTER, C.J. (2005). N17 Toll Road Project. Socio-Economic Impact Assessment.

The Treasury. (2005). Cost Benefit Analysis Primer Draft, Business Analysis Team, Version 1.12, New Zealand, Wellington. Also available on the site: http//www.treasury.govt.nz.

TRANSPORT NOTE. (2005). Note on the Evaluation of Transport Projects, Transport Economics, Policy and Poverty Thematic Group, Transport Note No: TRN-21, World Bank, USA, Washington DC. Also available on the site:http//www.worldbank.org/transport/publicat/twu-45.pd4.

Watanaba, T, et al. (1987). The Highway Design and Maintenance Standard Model: Volume 1: Description Of The HDM-III Model. The World Bank. London and Baltimore. The John Hopkins University Press.

WORLD BANK. (2004). Road Economic Decision (RED) Model. Software User Guide \& Case Studies. Sub-Saharan Africa Transport Policy Program: SSATP Working Paper No.78. 